\title{
EXPERIMENTAL AND THEORETICAL STUDY OF ADIABATIC HUMIDIFICATION IN HVAC\&R APPLICATIONS
}

\section{ESTUDIO TEÓRICO EXPERIMENTAL DE LA HUMIDIFICACIÓN ADIABÁTICA EN APLICACIONES HVAC\&R}

\author{
Néstor Fonseca $^{1} \quad$ Cristian Cuevas $^{2}$ \\ Recibido 30 de diciembre de 2008, aceptado 7 de mayo de 2010 \\ Received: December 30, 2008 Accepted: May 7, 2010
}

\begin{abstract}
RESUMEN
Este artículo presenta los resultados del estudio realizado para obtener un tratamiento teórico unificado de la humidificación adiabática, aplicable a sistemas de refrigeración y acondicionamiento de aire con la cual generar una herramienta de cálculo que pueda ser utilizada en terreno como parte de su diagnóstico en auditorías energéticas de este tipo de sistemas. Para lograr esto se realizan una serie de ensayos y análisis de tipo experimental en dos diferentes clases de equipo. El modelo computacional permite predecir la efectividad del sistema y principales variables de salida como la temperatura y contenido de humedad mediante la medición de las condiciones de entrada de temperatura y flujos másicos de los fluidos que intervienen en la transferencia de masa y energía. La clave en el análisis es la definición del coeficiente global de transferencia de calor AU, considerando la influencia de los flujos de agua y aire en el sistema. Se describe un ejemplo de validación del modelo por cada tipo de sistema seleccionado en este estudio.
\end{abstract}

Palabras clave: Acondicionamiento de aire, refrigeración, auditoría energética, modelo computacional.

\begin{abstract}
This article presents the results of the study performed to obtain a theoretical unified treatment of adiabatic humidification to be applied in refrigeration and air conditioning systems that can be used as a calculate tool in field as a part of diagnosis in audit processes of this kind of systems. To achieve this, a series of tests and experimental analysis are performed on two types of systems. The computational model is able to predict the effectiveness of the system and the main variables at the system exhaust as temperature and humidity by using the measurement of temperature and mass flow rates that participle in the energy and mass and transfer. The key in the analysis is the global heat transfer coefficient AU, considering the influence of the water an air mass flow rates in the system. An example of each system considered in this study is shown, illustrating the validation of the model.
\end{abstract}

Keywords: Air conditioning, refrigeration, commissioning, computational model.

\section{INTRODUCTION}

There are two types of humidification processes commonly used in HVAC\&R applications: isothermal and adiabatic systems.

Isothermal humidification systems utilize heating energy to generate steam and to distribute it either in an air stream or directly into a room.

Adiabatic systems are widely used in computer rooms, hospitals, laboratories, museums and other spaces where controlling the humidity level is crucial for health, storage, or manufacturing. Humidifiers using this process, exchange sensible heat of air with latent heat of water to accomplish evaporation. The result is a drop in the air temperature while the air enthalpy remains almost constant. In other words, moisture is added to the air at the expense (or at the benefit) of a drop in the air temperature. When designing an adiabatic system, careful consideration must be made to the entering air temperature and humidity conditions. Since the process occurs at almost constant enthalpy, the air must be warm

\footnotetext{
1 Universidad Tecnológica de Pereira. Facultad de Ingeniería Mecánica. Colombia. E-mail: njfonseca@doct.ulg.ac.be
}

2 Universidad de Concepción. Facultad de Ingeniería. Departamento de Ingeniería Mecánica. Chile. 
enough to absorb enough moisture to achieve the desired space relative humidity. Therefore, the entering air typically needs to be preheated prior to the humidification, especially in colder climates and in systems with large amounts of outdoor air.

There are three general types of adiabatic humidifiers: evaporative coolers, wetted media, and water atomization. The main goal of this study is to develop a methodology and a simplified simulation model to determine the operating conditions and the effectiveness of this kind of equipment in situ, as part of a commissioning process of HVAC\&R systems.

General comparisons are often made to show how one humidifier is more efficient than the other, only on the basis of the energy required to generate steam or vapor. Little attention has been given to its effectiveness and to the effect of local climate on its behavior.

The most-used humidifier system models in the literature are based on heat and mass transfer balances of the specific humidifiers systems [1-4] and usually they are simplified to be incorporated into the more complex model of the HVAC systems. Most of them are adapted from HVAC 2 Toolkit model EVAPHUM [5].

This model uses a constant overall saturation transfer coefficient, $A \cdot U$, which is calculated in the parameter processing from rated values.

More detailed models were developed for specific humidifier systems, such as high-pressure humidification [6], or for desalination processes [7]. This paper shows that a "unified" theoretical treatment may be applied to two main types of adiabatic humidifiers: wetted media and water atomization.

The main goal of this study is to develop a methodology and a simplified simulation model to determine the operating conditions and the effectiveness of this kind of equipment in situ as part of a commissioning process of HVAC\&R systems.

\section{HUMIDIFIER EFFECTIVENESS}

Adiabatic humidification is characterized by negligible air enthalpy and wet bulb temperature variations between supply and exhaust of the humidifier system (Figure 1).

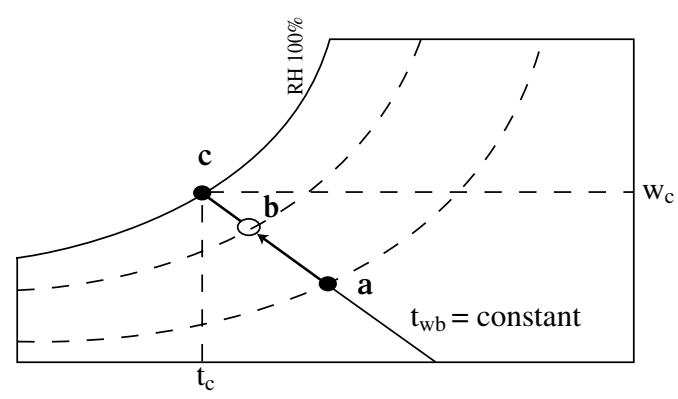

Figure 1. Adiabatic humidification process.

Like other mass and energy transfer processes, the air adiabatic humidification can be characterized by its effectiveness. The "wet" effectiveness of a humidification process could be defined as a function of the air humidity ratios $(X \cdot W)$ :

$$
\varepsilon_{h u m, w}=\frac{(X \cdot W)_{b}-(X \cdot W)_{a}}{(X \cdot W)_{c}-(X \cdot W)_{a}}
$$

With

a: Initial state (supply humidifier)

b: Real final State (exhaust humidifier)

c: Theoretical final state (ideal procedure)

$X$ : Humidity fraction in vapor phase, $\left[\mathrm{kg}_{\text {water vapor }}\right.$ $\mathrm{kg}_{\text {water total }}{ }^{-1}$ ]. ( $X=1$ corresponds to the conventional definition of air humidity ratio for a binary mixture of dry air and $100 \%$ water vapor (ASHRAE).

$X \cdot W$ :Air humidity ratio, $\left[\mathrm{kg}_{\text {water vapor }} \mathrm{kg}_{\text {dry air }}{ }^{-1}\right]$

The humidity ratio $\left(X \cdot W_{\mathrm{c}}\right)$ is calculated as a function of the temperature at saturated condition; the supply humidity ratio value $\left(X \cdot W_{a}\right)$ can be calculated, for example, by using the measured values of relative humidity and supply air temperature. $X$ takes into account the water that is still in liquid phase in the dry air/water vapor mixture: $X=1$ when there is no liquid water in the mixture and $X<1$ when there are some water droplets in the mixture.

Experimentally it has been demonstrated that a smaller uncertainty on the estimation of the air humidity ratio is obtained by measuring the dew point temperature [8]. However, in the commissioning process, this measuring device is not usually available.

The exhaust humidity ratio $\left(X \cdot W_{b}\right)$ should be calculated through energy and mass balances on humidifier control volume (Annex 1). Near saturation, the relative humidity measurement uncertainty increases significantly, because of the presence of water droplets in the air than can disturb this measurement. 
In fair approximation, measured supply and exhaust dry air temperatures can be used to calculate the humidifier "thermal" effectiveness as follows:

$$
\varepsilon_{\text {hum }, t}=\frac{t_{b}-t_{a}}{t_{c}-t_{a}}
$$

\section{EXPERIMENTAL SYSTEM}

In this work, effectiveness is estimated for two different adiabatic humidifiers: wetted media and water centrifugal atomizer. The wetted media humidifier (Figure 2) consists in 9425 wires of $2 \mathrm{~mm}$ of diameter providing a heat and mass transfer surface between air and water of $59.2 \mathrm{~m}^{2}$. The function of the cool battery and electric resistance in Figure 2 is the control of the supplied water conditions. In the atomizing humidifier (Figure 3), the water is passing through a basket, specially designed to generate very small and uniform size droplets. The water enters into the basket connected to the motor shaft, where it is pulverized by centrifugation. This system is located inside the main airstream, generating a plume whose shape varies with the air speed.

Both systems have being placed in different sections of the same test bench. It consists in an Air Handling Unit of classic conception (Figure 4).

The humidifier supply and exhaust conditions of temperature, relative humidity and mass flow rates (water and air) are measured, as well as temperature and humidity conditions at different points into the Air Handling Unit.

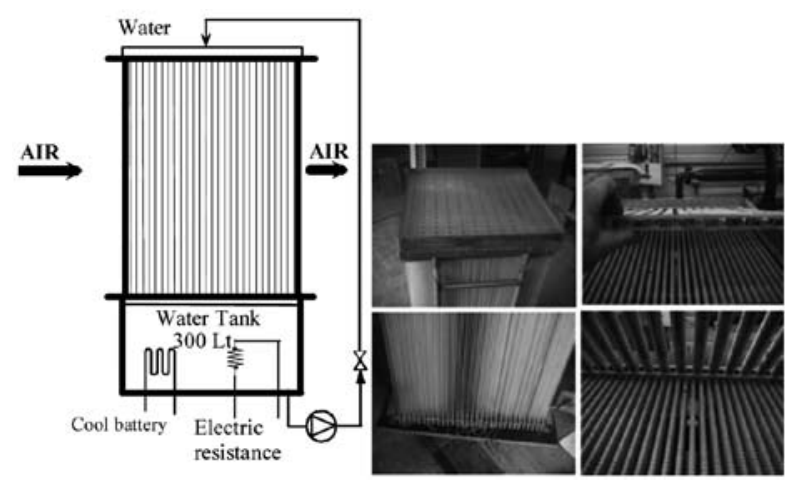

Figure 2. Functional scheme and pictures of the wetted media humidifier.

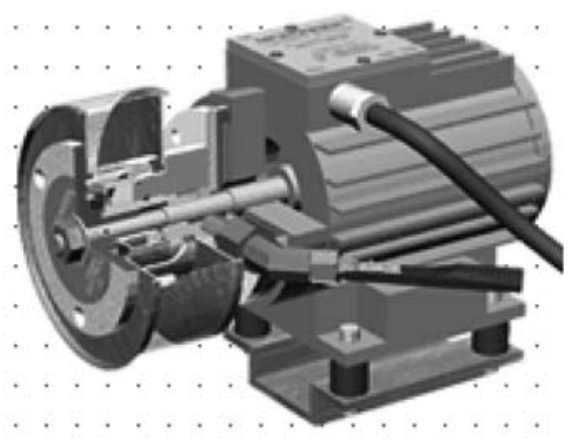

Figure 3. Functional scheme of atomizing humidifier.

All measurements are performed according to ANSI/ ASHRAE Standard 41.1-1986 (RA 91) [9], ASHRAE, ANSI/ASHRAE Standard 41.2-1987 (RA92) [10] and ANSI/ASHRAE Standard 41.3-1989 [11].

Table 1. Combined uncertainties.

\begin{tabular}{|c|c|}
\hline Variable & Combined uncertainty \\
\hline Temperatures & $\pm 0.25 \mathrm{~K}$ \\
\hline Water mass flow rates & $\begin{array}{c} \pm 0.2 \% \text { of the measured value } \\
\text { (timing the given mass flow) }\end{array}$ \\
\hline Air mass flow rate & $\begin{array}{c} \pm 0.5 \% \text { of the measured value } \\
\text { (ANSI/ASHRAE Standard } \\
41.1)\end{array}$ \\
\hline Relative humidity & $\pm 2 \%$ \\
\hline Barometric pressure & $\pm 0.2 \mathrm{hPa}$ \\
\hline
\end{tabular}

The method used here for uncertainty analysis is based on the Guide to the Expression of Uncertainty Measurement [12]; instrumental accuracies are given for a confidence level of $95 \%$. Table 1 gives the combined uncertainties (device and data acquisition system) of the main measurements.

\section{TEST RESULTS}

The test results obtained with both humidification systems are shown in Tables 2 and 3, for different levels of specific humidity ratio, water flow rate and supply air temperature.

From these results it is possible to observe that, for the humidifier considered, the difference between "thermal" and "wet" effectivenesses is negligible (average difference lower than $2 \%$ ). It is also confirmed that the difference between supply and exhaust water temperature is very small.

It is observed that to determine the "wet" effectiveness, the calculus process requires additional measurement of 


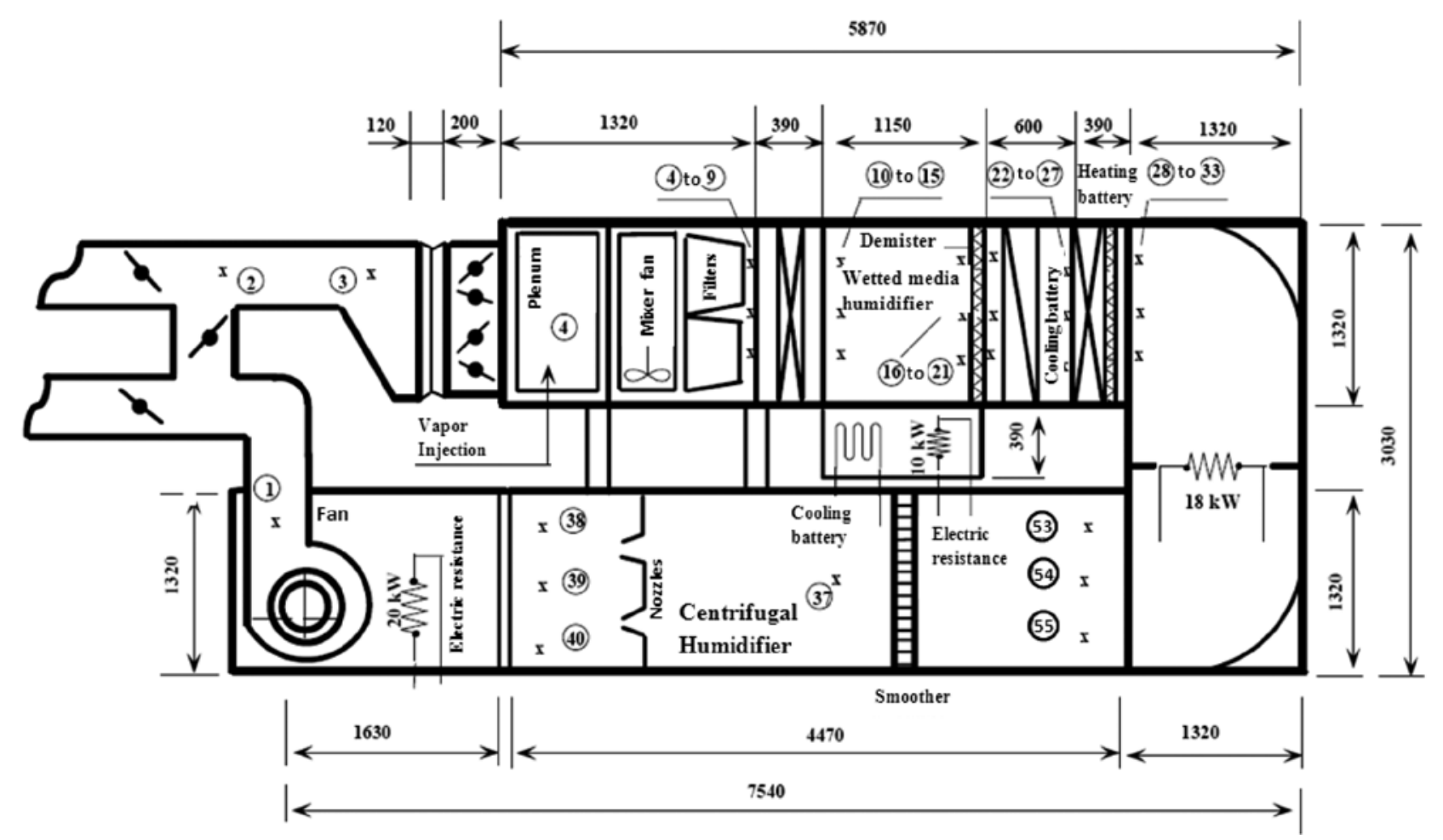

Figure 4. Details of the wetted media and centrifugal atomizing humidifiers test bench.

Table 2. Wetted wires humidifier-experimental and calculated values.

\begin{tabular}{|c|c|c|c|c|c|c|c|c|c|c|c|}
\hline \multirow{2}{*}{ Test $\mathbf{N}^{\circ}$} & $\mathbf{P}$ & $t_{a, s u, h u m}$ & $\mathbf{t}_{\mathrm{a}, \mathrm{ex}, \mathrm{hum}}$ & $\mathbf{w}_{\mathrm{a}, \text { su,hum }}$ & $\dot{m}_{w, e v}$ & $\mathbf{t}_{\mathrm{w}, \mathrm{ex}, \mathrm{hum}}$ & $\dot{M}_{a}$ & $\mathbf{w}_{\mathrm{a} \text {,ex,hum }}$ & $\mathbf{t}_{\mathrm{w}, \mathrm{su}, \mathrm{hum}}$ & $\varepsilon_{\text {hum,w }}$ & $\varepsilon_{\text {hum }, \mathrm{t}}$ \\
\hline & {$[\mathrm{Pa}]$} & {$\left[{ }^{\circ} \mathbf{C}\right]$} & {$\left[{ }^{\circ} \mathbf{C}\right]$} & [kg/kg] & {$[\mathrm{kg} / \mathrm{s}]$} & {$\left[{ }^{\circ} \mathbf{C}\right]$} & {$[\mathrm{kg} / \mathrm{s}]$} & {$[\mathrm{kg} / \mathrm{kg}]$} & {$\left[{ }^{\circ} \mathbf{C}\right]$} & {$[\%]$} & {$[\%]$} \\
\hline $0402 \mathrm{a} 3$ & 99600 & 22.6 & 11.7 & 0.0045 & 0.0073 & 10.8 & 1.66 & 0.0089 & 10.8 & 99.6 & 98.9 \\
\hline $0302 \mathrm{a} 3$ & 99700 & 22.5 & 12.0 & 0.0043 & 0.0069 & 11.2 & 1.65 & 0.0085 & 11.2 & 95.83 & 93.9 \\
\hline $3102 \mathrm{a} 3$ & 99600 & 12.2 & 5.0 & 0.0024 & 0.0066 & 4.1 & 2.35 & 0.0052 & 4.1 & 93.31 & 92.57 \\
\hline $2901 \mathrm{a} 3$ & 99600 & 13.1 & 8.4 & 0.0051 & 0.0043 & 7.4 & 2.28 & 0.0070 & 7.4 & 97.97 & 95.68 \\
\hline
\end{tabular}

Table 3. Centrifugal atomizing humidifier-experimental and calculated values.

\begin{tabular}{|c|c|c|c|c|c|c|c|c|c|c|c|c|}
\hline \multirow{2}{*}{ Test $\mathbf{N}^{\mathbf{o}}$} & \multirow{2}{*}{\begin{tabular}{|c|}
$\mathbf{P}$ \\
{$[\mathrm{kPa}]$} \\
\end{tabular}} & \multirow{2}{*}{\begin{tabular}{|c|}
$\mathbf{t}_{\mathrm{a}, \mathrm{su}}, \mathrm{hum}$ \\
{$\left[{ }^{\circ} \mathbf{C}\right]$} \\
\end{tabular}} & \multirow{2}{*}{\begin{tabular}{|c|}
$\mathbf{t}_{\mathrm{a}, \text { ex }, \text { hum }}$ \\
{$\left[{ }^{\circ} \mathbf{C}\right]$} \\
\end{tabular}} & \multirow{2}{*}{\begin{tabular}{|c|} 
wa,su,hum \\
{$[\mathrm{kg} / \mathrm{kg}]$} \\
\end{tabular}} & \multirow{2}{*}{$\begin{array}{c}\mathbf{t}_{\mathrm{w}, \mathrm{ex}, \mathrm{hum}} \\
{\left[{ }^{\circ} \mathbf{C}\right]} \\
\end{array}$} & \multicolumn{2}{|c|}{$\dot{M}_{w, s u, h u m}$} & \multirow{2}{*}{$\frac{\dot{M}_{a}}{[\mathrm{~kg} / \mathrm{s}]}$} & \multirow{2}{*}{$\begin{array}{l}\dot{M}_{w, \text { ex, hum }} \\
{[\mathbf{k g} / \mathbf{k g}]}\end{array}$} & \multirow{2}{*}{$\frac{\mathbf{w}_{\mathrm{a}, \text { ex,hum }}}{\%}$} & \multirow{2}{*}{$\frac{\varepsilon_{\text {hum w }}}{\%}$} & \multirow{2}{*}{$\begin{array}{l}\varepsilon_{\text {hum t }} \\
{[\mathrm{kg} / \mathrm{s}]} \\
\end{array}$} \\
\hline & & & & & & {$[\mathrm{kg} / \mathrm{s}]$} & {$[\mathbf{L} / \mathbf{h}]$} & & & & & \\
\hline 1109A & 99,6 & 24.7 & 19.8 & 0.0052 & 17.2 & 0.0133 & 48.0 & 2.62 & 0.0070 & 39.5 & 43.5 & 0.0086 \\
\hline $1209 \mathrm{~A}$ & 99,7 & 21.7 & 17.2 & 0.0051 & 17.0 & 0.0141 & 50.7 & 2.64 & 0.0069 & 44.3 & 46.4 & 0.0096 \\
\hline 1309A1 & 99,6 & 25.0 & 19.6 & 0.0052 & 18.4 & 0.0154 & 55.6 & 2.63 & 0.0071 & 41.5 & 46.8 & 0.0103 \\
\hline 1309A3 & 99,6 & 24.9 & 18.7 & 0.0052 & 1. & 0.0247 & 89.0 & 2.63 & 0.0075 & 4 & 54.4 & 0.0187 \\
\hline 1009A & 99,1 & 27.2 & 22.0 & 0.0054 & 22.0 & 0.0132 & 47.6 & 2.60 & 0.0074 & 38.9 & 40.8 & 0.0080 \\
\hline 1309A2 & 99,6 & 25.0 & 18.8 & 0.0054 & 15.8 & 0.0263 & 95.0 & 2.64 & 0.0078 & 54.1 & 54.5 & 0.0198 \\
\hline 1209B2 & 99,5 & 21.5 & 17.5 & 0.0060 & 17.5 & 0.0129 & 46.5 & 2.62 & 0.0075 & 42.3 & 45.8 & 0.0089 \\
\hline 1209B1 & 99,5 & 24.0 & 19.5 & 0.0062 & 18.0 & 0.0134 & 48.5 & 2.62 & 0.0079 & 42.5 & 46.7 & 0.0089 \\
\hline
\end{tabular}


water and air flow rates and evaporated water during the humidification process. As consequence, the uncertainty propagation analysis shows that "thermal" effectiveness has an expanded uncertainty of $\pm 2.9 \%$, whereas the humidifier "wet" effectiveness uncertainty is $\pm 7.5 \%$. It may be a problem if the measurements have to be performed in situ. The risk of error increases with the number of measured variables. "Thermal" effectiveness can be therefore a good alternative for commissioning and energy audit processes, since it's easier to estimate and presents a smaller risk of error.

\section{HUMIDIFIER MODELING}

The approach used in this study for the humidifier modelling is the one proposed by Lebrun, Winandy, Trebilcock and Aparecida [13]. They proposed a simplified model for (direct or indirect) evaporation cooling equipment by considering it as a classic heat exchanger working with a fictitious moist fluid, characterized by a fictitious specific heat.

Adiabatic humidifiers can be considered as a particular case of a direct contact evaporative cooling system. In the present case, the water can be considered as a quasiisothermal fluid.

The model developed here considers an air flow rate passing through wet elements or through pulverized water, which is characterized by a mass and heat transfer in a process considered at a constant wetbulb temperature $t_{w b}$. Figure 5 shows the water and air temperature evolution during the adiabatic humidification process.

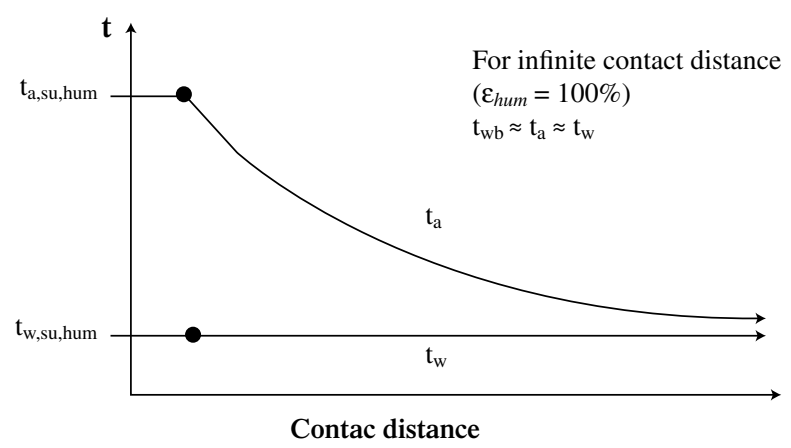

Figure 5. Water and air temperature evolution during the adiabatic humidification process

\section{Mathematical model description}

The humidifier exhaust air temperature is calculated using the $\varepsilon$-NTU method, defined by the following equation:

$$
t_{a, \text { ex }, \text { hum }}=t_{a, \text { su, hum }}+\left(t_{w b, \text { su,hum }}-t_{a, \text { su,hum }}\right) \cdot \varepsilon_{\text {hum }}
$$

The model determines the effectiveness by considering the evaporative source as having an infinite capacity flow rate:

$$
\varepsilon_{\text {hum }}=1-\exp (-N T U)
$$

With:

$$
N T U=\frac{A \cdot U}{\dot{C}_{\min }}
$$

In this particular case, the minimal thermal capacity flow rate is on the air side.

$$
\dot{C}_{\min }=\dot{C}_{a}
$$

With:

$$
\dot{C}_{a}=\dot{M}_{a, s u, h u m} \cdot c_{p, a}
$$

The influences of both (air and water) flow rates can be approximated through the following equation:

$$
A \cdot U=A \cdot U_{n} \cdot\left[\frac{\dot{M}_{a}}{\dot{M}_{a, n}}\right]^{n} \cdot\left[\frac{\dot{M}_{w}}{\dot{M}_{w, n}}\right]^{m}
$$

With:

$A \cdot U_{n}$ : Overall heat transfer coefficient at nominal

$\dot{M}_{a, n} \quad$ : Air flow rate at nominal conditions.

$\dot{M}_{w, n} \quad$ : Water flow rate at nominal conditions.

The humidifier model can be characterized by the inputs, outputs and parameters shown in Figure 6.

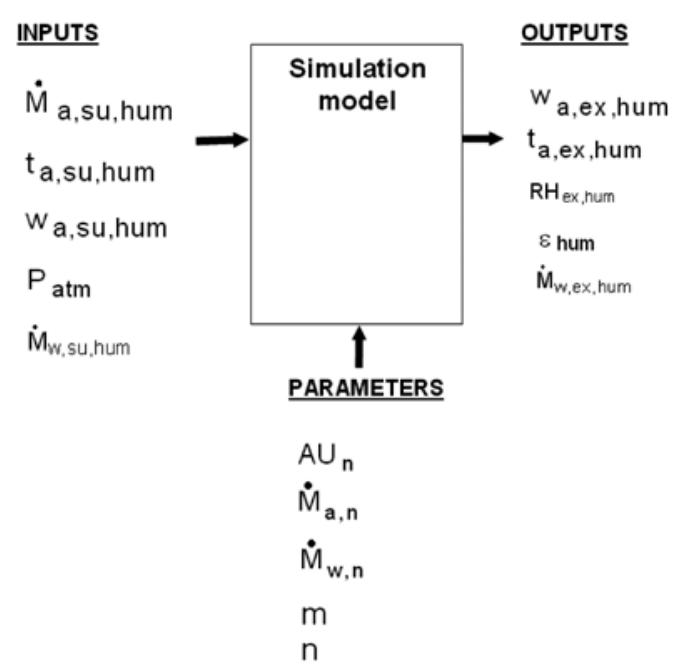

Figure 6. Inputs, outputs and parametres of the humidifier model. 
The model has 5 parameters: three of them $\left(A \cdot U_{n}, \dot{M}_{w, n}\right.$, $\left.\dot{M}_{a, n}\right)$ are obtained from manufacturer datasheet, whereas the two other ones ( $n$ and $m$ ) require some experiments [14-16].

The model parameters are identified as example in this article by using separately the 13 tests carried out with both humidifiers and by using the software EES [17]. The identified parameters are determined by minimization of the error between the measured and simulated air humidity ratio and temperature at the humidifier exhaust.

The model results for these conditions are shown in Figure 7 for a wetted media humidifier and in Figure 8 for a centrifugal atomizing humidifier.

For the wetted media humidifier, the average difference between experimental and predicted values of the air humidity ratio and temperature are \pm 0.1 [ $\mathrm{g}_{\text {water vapor }}$ $\left.\mathrm{kg}_{\text {dry air }}{ }^{1}\right]$ and $0.01[\mathrm{~K}]$ respectively. For the centrifugal atomizing humidifier: \pm 0.2 [g $\mathrm{g}_{\text {water vapor }} \mathrm{kg}_{\mathrm{dry}_{\text {air }}}{ }^{1}$ ] and $0.03[\mathrm{~K}]$ respectively.
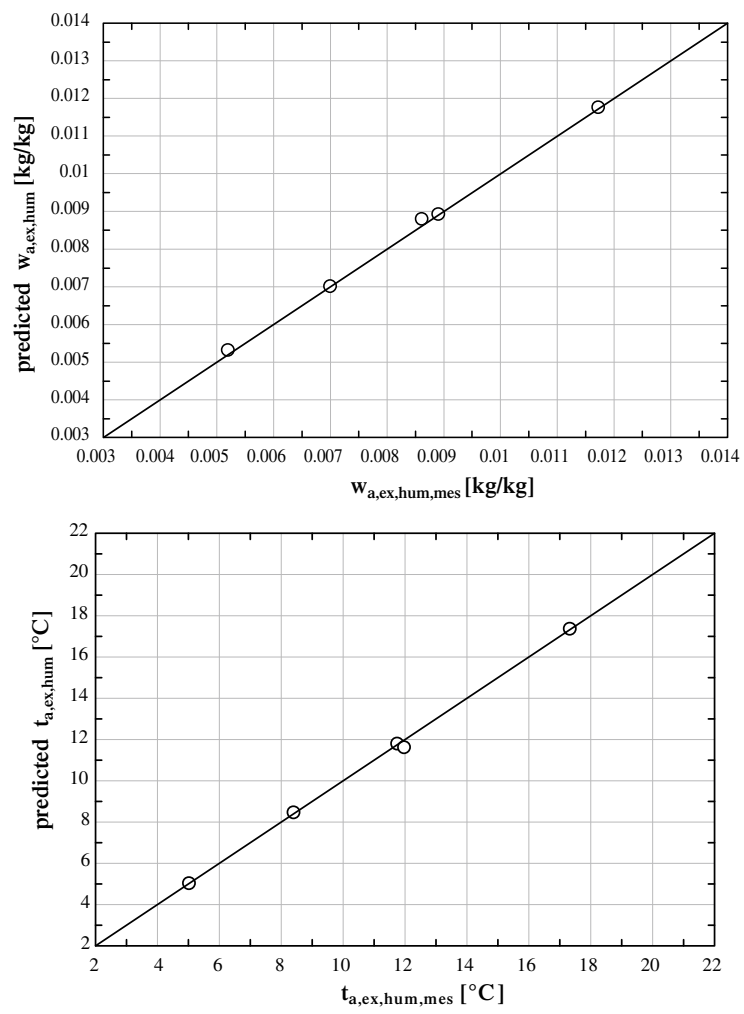

Figure 7. Simulated versus measured temperature and humidity ratio at the exhaust of wetted media humidifier.
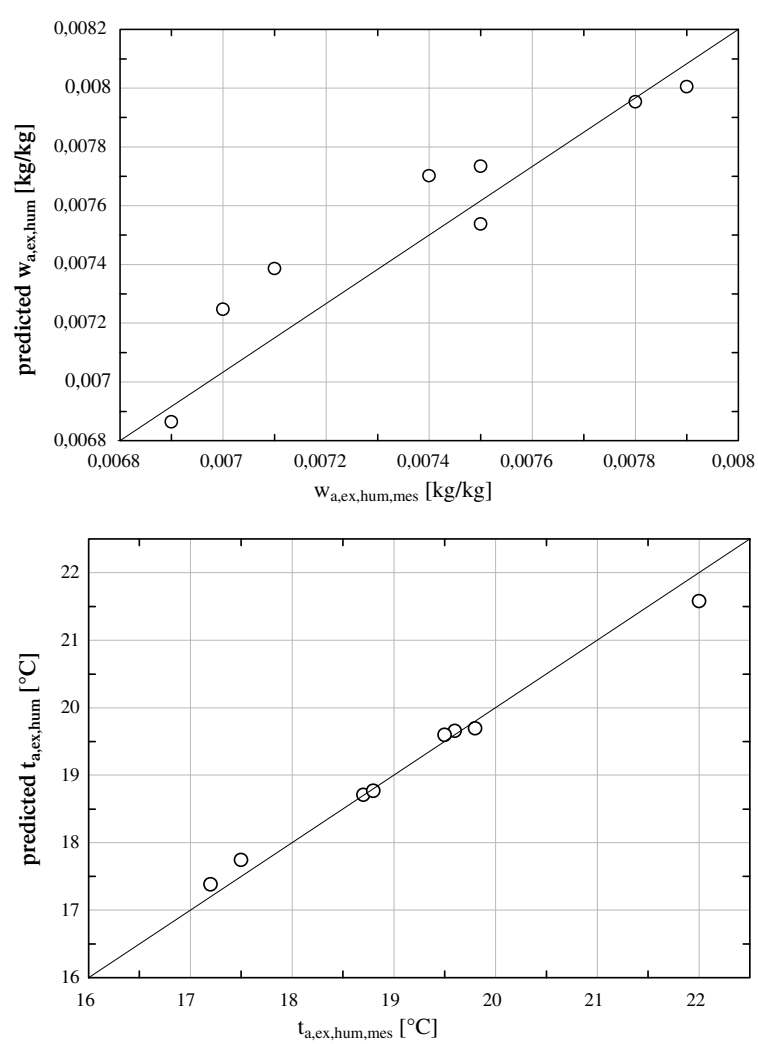

Figure 8. Simulated versus measured temperature and humidity ratio at the exhaust for centrifugal.

The parameters identified are the followings:

\section{Wetted wires humidifier:}

Nominal flow rates:

$\dot{M}_{a, n}=1.6\left[\mathrm{~kg} \mathrm{~s}^{-1}\right]$

$\dot{M}_{w, n}=2.5\left[\mathrm{~kg} \mathrm{~s}^{-1}\right]$

Domain covered in laboratory tests.

Constant water flow rate: $2.5\left[\mathrm{~kg} \mathrm{~s}^{-1}\right]$

Air flow rate varying from $1.7\left[\mathrm{~kg} \mathrm{~s}^{-1}\right]$ to $3.3\left[\mathrm{~kg} \mathrm{~s}^{-1}\right]$.

Results of the parameter identification:

$A \cdot U_{n}=7646\left[\mathrm{~W} \mathrm{~K}^{-1}\right]$

$\mathrm{n}=0.5$

$\mathrm{m}=0$

\section{Centrifugal atomizing humidifier:}

Nominal flow rates:

$\dot{M}_{a, n}=2.5 \mathrm{~kg} \mathrm{~s}^{-1}$

$\dot{M}_{w, n}=0.013 \mathrm{~kg} \mathrm{~s}^{-1}$

Domain covered in laboratory tests.

Constant air flow rate: $2.6\left[\mathrm{~kg} \mathrm{~s}^{-1}\right]$ 
Water flow rate varying from $0.012\left[\mathrm{~kg} \mathrm{~s}^{-1}\right]$ to 0.024 $\left[\mathrm{kg} \mathrm{s}^{-1}\right]$

Results of the parameter identification:

$$
\begin{aligned}
& A \cdot U_{n}=1500\left[\mathrm{~W} \mathrm{~K}^{-1}\right] \\
& \mathrm{n}=0.771 \\
& \mathrm{~m}=0.4718
\end{aligned}
$$

Figure 9 presents the results of the identification process for the wetted wires humidifier.

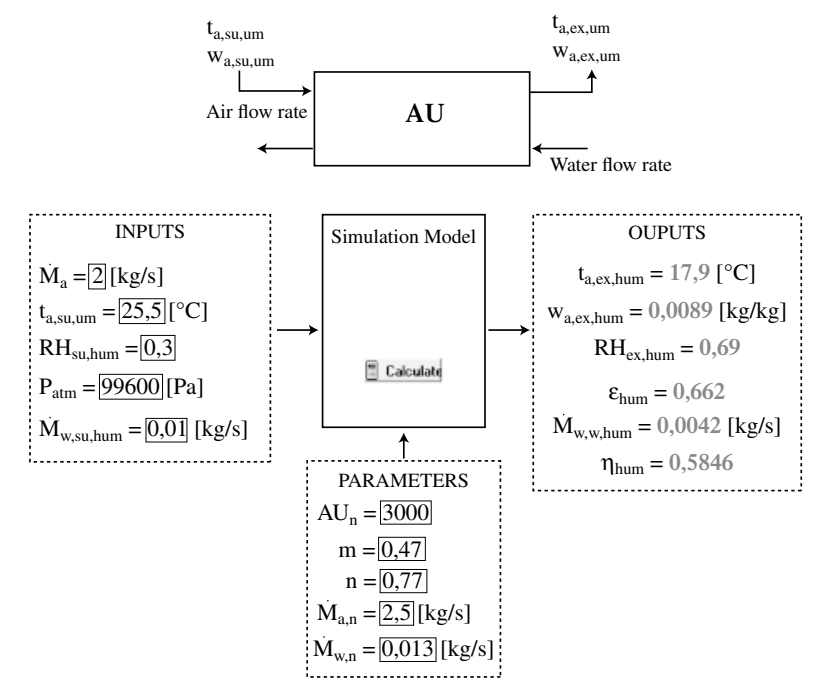

Figure 9. Results diagram for wetted wires humidifier.

\section{CONCLUSIONS}

The modeling and experimental validation of two humidifier systems are presented here as a part of a study of the adiabatic humidification. A good agreement between the simulated and measured values was found. The results show that humidifier effectiveness can be calculated with an uncertainty of $\pm 2.9 \%$ and the average difference between simulated and measured air humidity ratio and temperature at the humidifier exhaust are lower than \pm 0.17 [ $\mathrm{g}_{\text {water vapor }} \mathrm{kg}_{\text {dry air }}{ }^{-1}$ ] and $\pm 0.03 \mathrm{k}$ respectively. The theoretical approach used for the modeling can be used for preliminary calculation, design, diagnosis and in situ commissioning of adiabatic humidifier: wetted media and centrifugal atomizing humidifiers.

According to our analysis, care must be taken on the vapor quality in the case of in situ measurements for commissioning processes. Near saturation, the relative humidity measurement uncertainty rises significantly due to the liquid droplets present in the air that disturbs the humidity measurement.
For adiabatic humidification processes, "thermal" effectiveness estimation can be a good alternative for commissioning and energy audit processes, considering that the number of required measurements is smaller, which produces also a reduced risk of error considering that the values of "thermal" and "wet" humidifier effectiveness are indeed in good agreement (average difference lower than $2 \%$ ).

\section{REFERENCES}

[1] International Energy Agency (IEA). "Models for Building Indoor Climate and Energy Simulation". A Report of Task 22. Building Energy Analysis Tools. December, 1999.

[2] F. Fermanel and J. Miriel. "Air heating system: influence of a humidifier on thermal comfort". Applied Thermal Engineering. Vol. 19, Issue 10, pp. 1107-1127. October, 1999.

[3] R.M. Barbosa and M. Mendes. "Combined simulation of central HVAC systems with a whole-building hygrothermal model". Energy and Buildings. Vol. 40, Issue 10, pp. 276-288. 2008.

[4] B. Tashtoush, M. Molhim and M. Al-Rousan. "Dynamic model of an HVAC system for control analysis". Energy. Vol. 30, Issue 10, pp. 17291745. July, 2005.

[5] M. Brandemuehl, S. Gabel and I. Andresen. "HVAC2 Toolkit: A toolkit for secondary HVAC system energy calculation". ASHRAE. Atlanta, Georgia, EEUU. 1993.

[6] Z. Xu, Y. Xiao and Y. Wang. "Experimental and theoretical studies on air humidification by a water spray at elevated pressure". Applied Thermal Engineering. Vol. 27, Issues 14-15, pp. 25492558. October, 2007.

[7] S.M. Soufari, M. Zamen and M. Amidpour. "Performance optimization of the humidificationdehumidification desalination process using mathematical programming". Desalination . Vol. 237, Issues 1-3, pp. 305-317. February, 2009.

[8] S.J. Slayzak and J.P. Ryan. "Instrument uncertainty effect on calculation of absolute humidity using dew point, wet-bulb, and relative humidity sensors". National Renewable Energy Laboratory Center for Building and thermal Energy Systems. Report Number: NREL/CP-550-24523 CONF-980641. Colorado, USA. 1998.

[9] ASHRAE. ANSI/ASHRAE Standard 41.1-1986 (RA 91). "Standard Method for Laboratory Airflow Measurement". American Society of Heating, 
Refrigeration and Air-Conditioning Engineers, Inc. 1991.

[10] ASHRAE. ANSI/ASHRAE Standard 41.2-1987 (RA 92). "Standard Method for temperature Measurement". American Society of Heating, Refrigeration and Air-Conditioning Engineers, Inc. 1992.

[11] ASHRAE. ANSI/ASHRAE Standard 41.3-1989. "Standard Method for Pressure Measurement". American Society of Heating, Refrigeration and Air-Conditioning Engineers, Inc. 1989.

[12] ISO GUM. "Guide to the Expression of Uncertainty in Measurement". Firsts Edition. 1993. Corrected and reprinted International Organization for Standardization. Geneva, Switzerland. 1995.

[13] J. Lebrun, E. Winandy, F. Trebilcock and C. Aparecida. "Simplified model for direct and indirect contact cooling towers and evaporative condensers". Building Services Engineering Research and Technology. Vol. 25, pp. 25-31. 2004.

[14] J.E. Braun, S.A. Klein, J.W Mitchell. "Effectiveness model for cooling tower and cooling coils". International journal of heat and mass transfer. Solar Energy laboratory. University of WisconsinMadison. 1998.

[15] X. Ding, J. Lebrun and M. Wasacz. "Cooling models to be used in transient and/or wet regimes, theoretical analysis and experimental validation". Proceedings of the system simulation in buildings conference. University of Liege. Belgium. 1991.

[16] ASHRAE HVAC."Systems and Equipment. Evaporative air cooling equipment and humidifiers". American Society of Heating, Refrigeration and Air-Conditioning Engineers, Inc. 2005.

[17] S. Klein and F. Alvarado. "EES-Engineering Equation Solver". Version 6.045, F-chart Software. Wisconsin, USA. 2001.

[18] C. Cuevas and J. Lebrun. "Re-commissioning of a cooling plant”. Faculty of Applied Sciences. University of Liege. Belgium. 2002.

\section{ANNEX}

\section{Wetted media humidifier mass and energy balances}

In order to calculate the required terms in equations 2 and 3 , it is necessary to carry out the mass and energy balances of humidifier system. The control volume used includes a section of the Air Handing Unit including its walls and humidifier wires (control volume A). A second energy balance (used as verification) is performed using a control volume that includes the water tank, pipework and the pump (volume B). The mass balance in the humidifier (main method) can be expressed by Equation A1:

$$
(X \cdot W)_{e x, h u m}=(X \cdot W)_{s u, h u m}+\frac{\dot{M}_{w, e v}}{\dot{M}_{d a}}
$$

Where:

$\dot{M}$ : Mass flow rate, $\left[\mathrm{kg} \mathrm{s}^{-1}\right]$

da: Dry air

ev: Evaporation

su: Supply

ex: Exhaust

hum: Humidification

w: water

In this balance, the influence of external air infiltration is not considered. The specific air flow rate $\dot{M}_{d a}$ is calculated as:

$$
\dot{M}_{d a}=\dot{V}_{a} \rho_{a, e x, h u m}
$$

Where:

$\rho$ : Density, $\left[\mathrm{kg} \mathrm{m}^{-3}\right]$

$\dot{V}:$ Volume flow rate, $\left[\mathrm{m}^{3} \mathrm{~s}^{-1}\right]$

a : Air

The $\dot{V}_{\text {a }}$ value is calculated from pressure differential (DP) measured across a bank of 6 nozzles as:

$$
\dot{V}_{a}=Y * C *\left(\sum A\right) * \sqrt{\frac{2 * D P}{\rho_{a, \text { ex }, \text { hum }, \text { total }}}}
$$

Where:

Y : Expansion factor for nozzles, calculated from tables [9] (dimensionless)

C : Nozzles discharge coefficient, calculated from tables [9] (dimensionless)

A : Nozzles exhaust area, $\left[\mathrm{m}^{2}\right]$

The energy balance of the control volume (A) gives:

$$
\begin{aligned}
& \dot{U}_{A}=\dot{M}_{d a} * h_{s u, h u m}+\dot{M}_{w, \text { ex hum }} * c_{w} *\left(t_{w, \text { su hum }}-t_{w, \text { ex }, \text { hum }}\right) \\
& +\dot{m}_{w, \text { ev }} * c_{w} * t_{w, \text { su,hum }}-\dot{M}_{d a} * h_{e x, \text { hum }}+\dot{Q}_{d \text { amb }}
\end{aligned}
$$

Where:

$\begin{array}{ll}\mathrm{c} & : \text { Specific heat, }\left[\mathrm{J} \mathrm{kg}^{-1} \mathrm{~K}^{-1}\right] \\ \mathrm{h} & : \text { Enthalpy, }\left[\mathrm{J} \mathrm{kg}^{-1}\right] \\ \dot{m} & : \text { Mass flow rate, }\left[\mathrm{kg} \mathrm{s}^{-1}\right] \\ \dot{Q} & : \text { Heat flow, }[\mathrm{W}] \\ \mathrm{amb} & : \text { Ambient }\end{array}$

c : Specific heat, [ $\mathrm{J} \mathrm{kg}^{-1} \mathrm{~K}^{-1}$ ]

h : Enthalpy, [ $\left.\mathrm{J} \mathrm{kg}^{-1}\right]$

$\dot{m}$ : Mass flow rate, $\left[\mathrm{kg} \mathrm{s}^{-1}\right]$

amb : Ambient 
$\dot{U}_{A}$ is the internal energy variation of the control volume (A). It can be estimated as:

$$
\dot{U}_{A}=C_{\text {com }} * \frac{d T_{a}}{d \tau}
$$

With:

$C_{\text {com }}$ : Global thermal mass of all components included in the control volume, $\left[\mathrm{J} \mathrm{K}^{-1}\right]$. It is given by the product of the mass and the average specific heat of the elements into the control volume (A).

$$
C_{\text {com }}=\left(m_{1} * c_{1}+m_{2} * c_{2} \ldots . . m_{n} * c_{n}\right)
$$

In the case considered, the corresponding internal energy variation of control volume is only around $1 \%$ of the air enthalpy flow rate, the uncertainty of this estimation can be neglected. $\frac{d T_{a}}{d \tau}: \begin{aligned} & \text { is the air temperature variation (supposed to } \\ & \text { represent the state variable, this hypothesis is }\end{aligned}$ used as the best estimation), $\left[\mathrm{K} \mathrm{s}^{-1}\right]$.

The differential $d T_{a} / d \tau$ is calculated by using the initial and final temperatures which are determined by averaging 5 points at the beginning and 5 other points at the end of each sampling period (steady-state), in such a way to define a period of 90 minutes [18].

The ambient loss $\dot{Q}_{a m b A}$ is calculated as:

$$
\dot{Q}_{a m b_{A}}=A \cdot U_{A} \cdot\left(t_{a m b}-t_{a, s u, h u m}\right)
$$

Where:

$\mathrm{U}$ : Overall heat transfer coefficient, [W $\left.\mathrm{m}^{-2} \mathrm{~K}^{-1}\right]$

In the case considered, the corresponding heat flow does not represent more than $0.2 \%$ of the air enthalpy flow rate; therefore the uncertainty of this estimation can be neglected.

The vapor quality $X$ (humidity fraction in vapor phase) can be calculated by Equations A4 and A8 considering that the exhaust and supply air and water conditions are known.

$$
\begin{aligned}
& h_{\text {ex, hum }, \text { cal }} \approx c_{p, a} * t_{a, \text { ex }, \text { hum }}+ \\
& {\left[X * c_{p, w v} * t_{a, e x, \text { hum }}+X * h_{f g, 0}+(1-X) * c_{w} * t_{a, e x, \text { hum }}\right]} \\
& * w_{\text {ex }, \text { hum }, \text { cal }}
\end{aligned}
$$

With:

$h_{f g, 0}$ : Liquid-vapor latent heat at $0^{\circ} \mathrm{C}(2501 \mathrm{~kJ} / \mathrm{kg})$.

$\mathrm{p}$ : Constant pressure

wv : Water Vapor

cal : Calculated

The humidity ratio $(X . W)$ can be defined as:

$$
X \cdot W=0.622 \cdot \frac{p_{w}}{p-p_{w}}
$$

Where:

$\mathrm{p}$ : Pressure, $[\mathrm{Pa}]$

The condition $X=1$, in Equation A9, corresponds to the conventional definition of the humidity ratio for a binary mixture of dry air and $100 \%$ water vapor [16]. The condition $\mathrm{X}<1$ considers that a part or the water can be still liquid at the end of the humidification process, therefore the tests with this condition are not considered here.

The energy balance of the control volume (B) gives:

$$
\begin{aligned}
& \dot{U}_{B}=\dot{M}_{w, e x, \text { hum }} * c_{w} *\left(t_{w, e x, \text { hum }}-t_{w, \text { su.hum }, 2}\right) \\
& -\dot{m}_{w, \text { ev }} * c_{w} * t_{w, \text { su }, \text { hum }}+\dot{W}_{\text {pump }}+\dot{Q}_{\text {dn } b}
\end{aligned}
$$

The ambient loss $\dot{Q}_{a m b B}$ is calculated also by Equation A7.

The humidifier "wet" effectiveness is evaluated with Equation 1. The humidifier maximum exhaust humidity ratio $\left(X \cdot W_{\mathrm{c}}\right)$, is calculated from supply conditions, by supposing an adiabatic humidification.

The "thermal" effectiveness can be calculated with Equation 2, by using the measured air temperatures. The maximum exhaust air temperature is calculated from supply conditions and considering an adiabatic humidification. This is just a checking, the "thermal" effectiveness should be almost the same as the "wet" effectiveness.

\section{Centrifugal humidifier mass and energy balances}

The control volume considered to carry out the energy and mass balances in this case, include the section of the Air Handing Unit delimited by its walls, where the equipment is installed.

The humidifier exhaust air humidity ratio is calculated from the mass balance using the following expression, similar to Equation 3: 


$$
(X \cdot W)_{e x, \text { hum }}=(X \cdot W)_{s u, \text { hum }}+\frac{\dot{M}_{w, \text { su,net }}}{\dot{M}_{d a}}
$$

The net water flow rate is calculated as the difference between supply and exhaust flow rates.

$$
\dot{M}_{w, s u, n e t}=\dot{M}_{w, s u}-\dot{M}_{w, \text { ex }, \text { hum }}
$$

The humidifier energy balance can be expressed by equation A13:

$$
\begin{aligned}
& \dot{U}=\dot{Q}_{a m b}+\dot{W}_{m o t}+\dot{M}_{d a} * h_{s u, h u m, c a l}+\dot{M}_{w, s u} * h_{s u, w, c a l} \\
& -\dot{M}_{w, \text { ex }, \text { hum }} * h_{e x, w, c a l}-\dot{M}_{d a} * h_{e x, h u m, c a l}
\end{aligned}
$$

The humidifier exhaust air enthalpy is calculated by Equation A8.

The derivative $\dot{U}$ is, in this case, calculated as follows:

$$
\dot{U}=\left(C_{a}+C_{m o t}+C_{c o m}\right) \frac{d T_{a}}{d \tau}
$$

Where:

$C_{a}:$ is the air thermal mass, $\left[\mathrm{J} \mathrm{K}^{-1}\right]$

$C_{m o t}:$ is the motor thermal mass, $\left[\mathrm{J} \mathrm{K}^{-1}\right]$

$C_{c o m}$ : is the average thermal mass of other components contained into the control volume (system control, pipework, cables etc.., [ $\left.\mathrm{J} \mathrm{K}^{-1}\right]$.

As the internal energy variation of the control volume is only around $1.2 \%$ of the air enthalpy flow rate, the uncertainty of this estimation can be neglected.

From humidifier energy balance, the $X$ value (humidity fraction in vapor phase) can be calculated considering that air and water exhaust and supply conditions are known.

Finally the "wet" and "thermal" effectivenesses are calculated in the same way as for the wetted media humidifier (Equations 1 and 2). 